\title{
Future Prospects of Carbon Nanotubes Reinforced Metal Matrix Composite
}

\author{
Liang Tian, Liangfu Zheng*, Luyang Ren and Quanfang Chen \\ Department of Mechanical and Aerospace Engineering, University of Central Florida, USA
}

*Corresponding author: Liangfu Zheng, Department of Mechanical and Aerospace Engineering, USA

Submission: 監 December 12, 2017; Published: 韭 January 19, 2018

\begin{abstract}
Due to their high specific strength, and excellent thermal and electrical properties, carbon nanotubes (CNTs) reinforced metal matrix composites possess a huge potential to be widely used in structural and functional applications, such as automobile, aerospace, sports, microelectrochemical systems (MEMS), sensors, battery, and energy storage [1]. However, processing of CNTs reinforced metal matrix composite with advanced properties has been a challenge due to the difficulties in obtaining good dispersion of well-aligned and intact CNTs inside the matrix without chemical degradation. This review highlights the challenges and provides guidance for future research directions in CNTs reinforced metal matrix composite.
\end{abstract}

\section{Mini Review}

Carbon nanotubes (CNTs) have an excellent combination of mechanical, electrical, and thermal properties that make it a perfect reinforcement for composite material [2,3]. For examples, Young's modulus of single-walled carbon nanotubes (SWCNTs) and multi-walled carbon nanotubes (MWCNTs) are 2.8-3.6TPa and 1.7-2.4TPa, [4] respectively, which are approximately 10 times that of steel [5]. Electrical conductivity of CNTs is roughly 2 orders of magnitude higher than that of Ag, the best conductor in metals [6]. Application of CNTs as a reinforcement material for polymers has been well studied due to the ease of improving their electrical and mechanical properties [7], however, CNTs reinforced metal matrix composite has remained a challenge to a wide range of researcher because of the intrinsically good mechanical, electrical, and thermal properties of metals [8].

CNTs can be synthesized by, for examples, arc-discharge, laser ablation, gas-phase catalytic growth from carbon monoxide, and chemical vapor deposition (CVD) from hydrocarbons [3]. Although only a small fraction of CNTs (e.g., 1 wt.\% (weight percent)) may be needed to significantly improve the properties of metal matrix if successful, large quantity of CNTs would be required for the purpose of industrial scale-up, which in turn requires an improvement in their production methods such as the arc discharge and laser ablation to make it cost-effective.

\section{Fabrication Challenges}

Figure 1 shows an example fabrication process of CNTs reinforced Cu matrix nanocomposite [9]. The challenges associated with CNTs reinforced metal matrix composite include CNTs' dispersion, damage (e.g., defects and metal carbides formation), interfacial bonding to matrix, and alignment. The first challenge lies in the fact that it is hard to disperse CNTs well inside the metal matrix to prevent formation of large CNTs clusters or aggregates due to their electrostatic and van der Waals forces as well as the density difference between CNTs and metal matrix [8]. Presence of CNTs clusters in processed composites, especially when CNTs are more than $1 \mathrm{wt} . \%$, has often led to reduction in the properties instead of improvement. For example, effect of CNTs agglomeration on the conductivity of matrix has been studied by Taylton et al. [10]. They found that when the CNTs concentration is close to the percolation threshold, a more uniform CNTs distribution can be achieved and lead to an enhanced conductivity. Extensive efforts have been put to find effective techniques to improve dispersion of CNTs within the matrix including high energy ball-milling, surfactants, and metal encapsulated CNTs composite precursors (e.g., molecular-level mixing, electroless deposition, and electrochemical deposition) $[8,9,11,12]$ Although some progress has been made, it is still a big challenge to get optimum parameters for these dispersion techniques in order to have uniform dispersion of CNTs in metal matrix while preventing degradation of CNTs.

A second challenge is to preserve an intact CNTs structure in the processed composite to maximize their reinforcement effects. For the purposes of clean and/or dispersion, pretreatments of CNTs by, for examples, acidic, thermal, mechanical, and chemical methods, are normally required prior to be used for composite fabrication [13]. This may cause significant damage to CNTs and subsequently reduce their unique properties [14].Therefore, optimum parameters of pretreatment need to be studied to address 
the tradeoff between advanced CNTs dispersion and CNTs damage. In addition, heat treatment processes, e.g. sintering, are normally required for fabrication of metal matrix composite, which may cause degradation of CNTs by, for example, formation of metal carbides such as aluminum carbide [15].

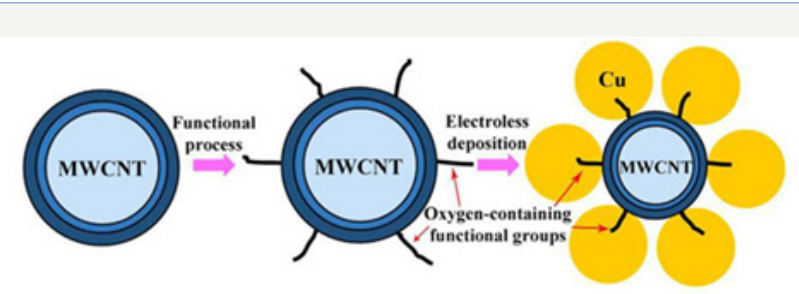

(a)

(b)

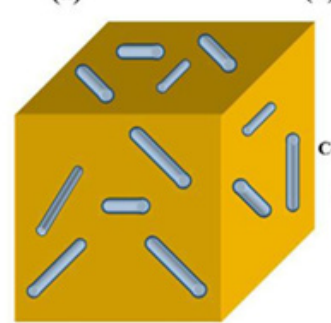

(e) (c)

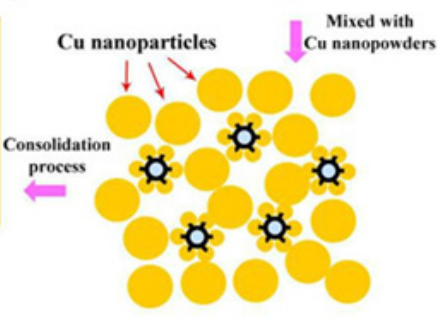

(d)
Figure 1: Schematics of fabrication processes of MWCNT reinforced $\mathrm{Cu}$ matrix nanocomposite.
a) Purified MWCNT,
b) Functionalized MWCNTs,
c) Cu encapsulated MWCNT,
d) $\mathrm{Cu}$ encapsulated MWCNT mixed with pure $\mathrm{Cu}$ nanoparticles, and
e) Fabricated MWCNT reinforced $\mathrm{Cu}$ nanocomposite [9].

A third challenge is to obtain an excellent interfacial bonding between CNTs and metal matrix. A CNTs-metal matrix bonding at or near the atomic length scale is normally required for good mechanical, electrical, and thermal performances of the processed composite, [16,17] otherwise debonding and subsequently increased phonon-electron scattering at the composite interface may occur during service to deteriorate the overall properties. The interfacial bonding between CNTs and metal matrix might be improved by pre-coating CNTs with, e.g., metals [18].

Another challenge is to achieve good alignment of CNTs in the metal matrix composite [8]. Well-aligned CNTs would bring a tremendous chance to improve the composite properties since the properties of CNTs along their axis are much better than those of their radial direction. For example, measurements have shown that an individual SWNT has a room-temperature thermal conductivity along its axis of about $3500 \mathrm{Wm}-1 \mathrm{~K}-1$, [19] but only about $1.52 \mathrm{Wm}$ $1 \mathrm{~K}-1$ in the radial direction [20]. Although some deformation processes techniques such as extrusion, rolling, and equal-channel angular processing, [1] may be able to align CNTs to some extent in the composite, more attention needs to be paid to explore successful processing techniques to achieve better CNTs alignment.

\section{Future Prospects}

Therefore, a successful development of a production process that promotes a uniform dispersion as well as alignment of CNTs in the matrix, without damaging them, is essential for obtaining metal matrix-CNTs nanocomposites with excellent mechanical and physical properties, and of course a significant advancement in the future manufacturing of CNTs reinforced metal matrix composite when compared to the current methods of powder metallurgy, melting and solidification, thermal spray, and electrochemistry [1].

\section{Acknowledgement}

This work was supported by the Department of Energy (DOE, Project Grant No. DE-EE0007864) and the University of Central Florida Preeminent Postdoctoral Program (P3) (Project No. 16269134 and 16269135).

\section{References}

1. Bakshi SR, Lahiri D, Agarwal A (2010) Carbon nanotube reinforced metal matrix composites-a review. International Materials Reviews 55(1): 41-64.

2. Baughman RH, Zakhidov AA, de Heer WA (2002) Carbon nanotubes--the route toward applications. Science 297(5582): 787-792.

3. Thostenson E, Ren Z, Chou TW (2001) Advances in the science and technology of carbon nanotubes and their composites: a review. Composites Science and Technology 61(13): 1899-1912.

4. Lourie O, Wagner HD (2011) Evaluation of young's modulus of carbon nanotubes by micro-raman spectroscopy. Journal of Materials Research 13(9): 2418-2422.

5. Chen Z, Gandhi U, Lee J, Wagoner RH (2016) Variation and consistency of Young's modulus in steel. Journal of Materials Processing Technology 227(Supp C): 227-243.

6. Ebbesen TW, Lezec HJ, Hiura H, Bennett JW, Ghaemi HF (1996) Electrical conductivity of individual carbon nanotubes. Nature 382: 54-56.

7. Spitalsky Z, Tasis D, Papagelis K, Galiotis C (2010) Carbon nanotubespolymer composites: Chemistry, processing, mechanical and electrical properties. Progress in Polymer Science 35(3): 357-401.

8. Neubauer E, Kitzmantel M, Hulman M, Angerer P (2010) Potential and challenges of metal-matrix-composites reinforced with carbon nanofibers and carbon nanotubes. Composites Science and Technology $70(16)$ : 2228-2236.

9. Wang H, Zhang ZH, Hu ZY, Wang FC, Li SL, et al. (2016) Synergistic strengthening effect of nanocrystalline copper reinforced with carbon nanotubes. Scientific Reports 6.

10. Tarlton T, Sullivan E, Brown J, Derosa PA (2017) The role of agglomeration in the conductivity of carbon nanotube composites near percolation. Journal of Applied Physics 121(8).

11. Cha SI, Kim KT, Arshad SN, Mo CB, Hong SH (2005) Extraordinary strengthening effect of carbon nanotubes in metal-matrix nanocomposites processed by molecular-level mixing. Advanced Materials 17(11): 1377-1381.

12.Zheng L, Sun J, Chen Q (2017) Carbon nanotubes reinforced copper composite with uniform CNT distribution and high yield of fabrication. Micro \& Nano Letters 12(10): 722-725.

13. Ma PC, Siddiqui NA, Marom G, Kim JK (2010) Dispersion and functionalization of carbon nanotubes for polymer-based nanocomposites: A review. Composites Part A: Applied Science and Manufacturing 41(10), 1345-1367.

14. Datsyuk V, Kalyva M, Papagelis K, Parthenios J, Tasis D, et al. (2008) Chemical oxidation of multiwalled carbon nanotubes. Carbon 46(6): 833-840. 
15. Ci L, Ryu Z, Jin-Phillipp NY, Rühle M (2006) Investigation of the interfacial reaction between multi-walled carbon nanotubes and aluminum. Acta Materialia 54(20): 5367-5375.

16. Shin SE, Choi HJ, Hwang JY, Bae DH (2015) Strengthening behavior of carbon/metal nanocomposites. Scientific Reports 5: 16114.

17. Choi BK, Yoon GH, Lee S (2016) Molecular dynamics studies of CNTreinforced aluminum composites under uniaxial tensile loading. Composites Part B: Engineering 91(Supp C): 119-125.

18. Byengsoo L, Chul-ju K, Bumjoon K, Untae S, Seyoung O, et al. (2016)
The effects of interfacial bonding on mechanical properties of singlewalled carbon nanotube reinforced copper matrix nanocomposites. Nanotechnology 17(23): 5759.

19. Pop E, Mann D, Wang Q, Goodson K, Dai H (2006) Thermal conductance of an individual single-wall carbon nanotube above room temperature. Nano Letters 6(1): 96-100.

20. Sinha S, Barjami S, Iannacchione G, Schwab A, Muench G (2005) Off-axis thermal properties of carbon nanotube films. Journal of Nanoparticle Research 7(6): 651-657. 